\title{
Perspectives on Physiotherapy Guidelines for Chronic Low Back Pain
}

\author{
ABSTRACT: The prevalence of chronic low back pain presents a world wide \\ dilemma to patients, physiotherapists and clinicians. There is scant evidence for \\ prevention and treatment however it is now acknowledged that the use of \\ physiotherapy in a multidimensional context has proved the more appropriate \\ model as a vital component of the collaborative approach required for effective \\ pain management.

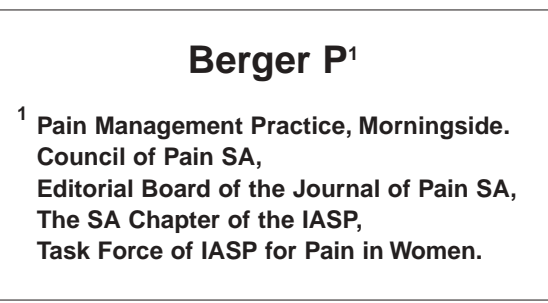

The following article reviews the current literature, evaluates and combines the guidelines that have been proposed from various international studies to provide a practical approach to the management of chronic back pain. This approach recognizes a broad biopsychosocial model of health and the positive role of activity in health and healing with emphasis on function, rather than impairment. Therefore the development of a patient-centred rehabilitative approach has emerged that emphasizes the restoration of normal movement and function with the addition of physical modalities where appropriate. Recent advances in neurophysiology, the modulation of pain and its perception and the fact that biological systems are known to be greatly affected by electrical treatment provide a clearer rationale for the use of physical agents for rehabilitation of patients with pain and related disability. The modalities used in conjunction with active exercises include thermal, massage, electrical stimulation, traction, transcutaneous electrical nerve stimulation (Tens), myofascial release, dry needling, mobilization and acupuncture. An algorithm is provided with the intention of developing protocols for breaking the pain cycle in both nociceptive and neuropathic pain states and in reducing inflammation which is a component of both peripheral and central sensitization. Pain rehabilitation is a useful and cost-effective approach to chronic pain management and makes patients' responsible partners in their own progress. It encourages planning, pacing of activities and activity related goal setting into a clear and goal-oriented context that provides the patient with control and improved quality of life.

\section{KEY WORDS: CHRONIC LOW BACK PAIN, GUIDELINES, PATIENT- CENTRED REHABILITATION, PHYSICAL MODALITIES, ALGORITHM.}

Low back pain is so common that it will affect almost everyone at some time (Dionne, 1999) and it remains the primary cause of absenteeism and disability in every industrialized society (Waddell, 1998). Patients who develop chronic low back pain and disability persisting beyond 3 months, will use more than $80 \%$ of all health care (Waddell, 1998).

The information above reveals the difficulties in prevention (the risk factors) and the lack of evidence for treatment. It appears that there are many confounding components that may act simultaneously or singly occurring within the individual that promote the chronicity of low back pain. Pain severity, extent of the accompanying disability, a previous disabling episode and overall course of the pain so far, and longer duration of the episode before it reaches primary care, all increase the likelihood that the condition will become persistent (Croft and Dunn, 2007). There may be a natural history or trajectory of any one individual's pain over a period of time or during the course of their life. This is a phenomenon well known in cardiovascular epidemiology that patients on a particular track in a chronic illness tend to stick to it and baseline severity and duration may simply be measuring the point the patient has reached on their track with little current evidence that treatment has a major effect in shifting this long term trajectory (Von Korff and Miglioretti, 2005).

An important study on exercise, spinal manipulative therapy and motor control exercise is described below that highlights the dilemma faced by physiotherapists on deciding best treatment practice for chronic low back pain. Despite considering the many factors that create difficulties in developing guidelines it is suggested that analyzing evidence from the various studies mentioned below, following concepts and suggested guidelines that have been approved by the International Association for the Study of Pain (IASP) and observing through clinical experience the results obtained at the 'coalface', provides physiotherapists with insight and information that may be useful in developing protocols that may improve the quality of life of many of their patients.

\section{CORRESPONDENCE TO:}

Phyllis Berger

Pain Management Practice

Ground Floor Block F

Rochester Place,

173 Rivonia Road

Morningside

PO Box 1839, Gallo Manor 2052

Tel: (011) 883-2000 (w), (011) 883-2006 (h)

Fax: (011) 883-3111

Email: pberger@icon.co.za 
Chronic low back pain is commonly treated with exercise or spinal manipulative therapy (Ferreira et al, 2002). The European Guidelines for Management of Chronic Non-specific Low Back Pain (Airaksinen et al, 2006) recommend supervised exercise therapy as a first-line treatment. These same guidelines recommend that a short course of spinal manipulative therapy should be considered as a treatment option. There have been no randomized head-to-head comparisons of the effects of general exercise and spinal manipulative therapy for the management of chronic low back pain so it is not clear which treatment is most effective.

Exercise programmes for chronic low back pain may be designed to reverse de-conditioning or the fear of movement associated with pain, or both. Such exercise programmes are often conducted in groups and typically include aerobic exercise such as walking or stationary cycling, as well as stretching and strengthening exercises (Hayden et al, 2005). Recently a distinctly different approach to exercise has been developed (Richardson et al, 1999) referred to as motor control exercise, aiming to retrain optimal control of spinal motion, usually practiced under one-to-one supervision, sometimes using ultrasound imaging to provide biofeedback of muscle contraction (Hides et al, 1995; Teyhen et al, 2005). A recent systematic review of the effects of motor control exercise for spinal pain showed that motor control exercise is more effective than medical management and education in the management of chronic non-specific low back pain. However the review did not identify any randomized headto-head comparisons of the effects of general and motor control exercise in patients with chronic low back pain, so it is not clear which of these interventions is more effective for this patient group (Ferreira et al., 2006).

The available evidence provides little guidance to clinicians who need to decide which interventions to implement for chronic low back pain. As there is little basis on which to prefer manipulative therapy or exercise therapy either general or motor control exercise, a randomized clinical cohort trial was conducted to compare the effects of general exercise, spinal manipulative therapy and motor control exercise for chronic low back pain by schools of physiotherapy in universities in Brazil (2 schools), Australia (3 schools) by Ferreira et al, (2007).

Two hundred and forty adults with non-specific low back pain, longer than 3 months duration were allocated to groups that received 8 weeks of general exercise, motor control exercise or spinal manipulative therapy. General exercise included strengthening, stretching and aerobic exercises. Motor control exercise involved retraining specific trunk muscles using ultrasound biofeedback. Spinal manipulative therapy included joint mobilization and manipulation. Primary outcomes were patientspecific function and global perceived effect at 8 weeks. These outcomes were also measured at 6 and 12 months, with follow-up of $93 \%$ and $88 \%$ at 6 and 12 months. The motor control exercise group had slightly better outcomes than the general exercise group at 8 weeks, as did the spinal manipulative therapy group. However all groups had similar outcomes at 6 and 12 months. The conclusion was that motor control exercise and spinal manipulative therapy produce slightly better short-term function and perceptions of effect than general exercise, but not better medium or long term effects in patients with chronic non-specific back pain (Ferreira ML. et al, 2007).

\section{FACTORS THAT MAY INFLUENCE CHRONIC LOW BACK PAIN ARE:}

- Physical fitness may be a key factor for prevention because of its effect on both onset and persistence and its relevance to other public health concerns (Lahad et al, 1994).

- Enthoven's study (2006) suggests that previous vigorous physical activity reduces the risk of long-term disability in those with low back pain and predicts longer-term disability in association with high rates of work loss and early retirement.

- Rapid and effective early management (and relief) of acute back pain may reduce the risk of future episodes, although there is little evidence that this occurs and most treatments that improve short-term outcome do not provide much long term advantage.

- Linton (2000) has identified psychosocial factors that may promote chronicity in primary care studies however these factors may have arisen from previous pain experience.

- Studies have identified that both affect (anxiety and depression) and cognition (catastrophising for example) increase the risk of back pain chronicity and vice versa (Grotle et al, 2005).

- Dissatisfaction with work is a consistent predictor of poor outcomes (Linton, 2001).

- Cognitive and behavioural interventions have not yet achieved dramatic improvements although they appear to increase therapist and patient satisfaction and reduce costs of care (Hay et al, 2005; Jellema et al, 2005).

- Confident physiotherapy in which the patient believes may have as much effect as specialized psychological interventions (Kalauokalani et al, 2001).

- Similarly positive effects may be achieved by self-care, sources of simple advice such as a Back Book, and in addition, being given a choice and getting a treatment that is preferred (Kalauokalani et al, 2001).

- Techniques that emphasize self-management with good information is humane and patient centred inducing a cultural shift away from 'medicalising' the condition (Kalauokalani et al, 2001). This may reduce chronicity and change expectations towards maintaining desirable activity and away from notions of cure and hopefully towards redefining a good prognosis.

It is evident that there are many factors that create difficulties in developing physiotherapy guidelines for chronic low back pain. One of the difficulties in generalizing results across studies is that outcome measures are often not comparable and may not permit general conclusions (Nielson and Weir, 2001). A systemic review of Exercise Therapy for Low Back Pain within the framework of the Cochrane Collaboration Back 
Review Group concluded that exercises may be helpful for patients with chronic low back pain to increase return to normal daily activities and work (van Tulder et al 2000). Many studies of physical treatments for chronic low back pain have not produced conclusive results including a RCT of physiotherapy compared with advice for low back pain concluding that physiotherapy was no more effective than one session of assessment and advice from physiotherapists (Frost et al 2004).

A study by Bousema et al (2007) has demonstrated that after one year patients with chronic persisting low back pain show no signs of de-conditioning and there is sufficient evidence that reconditioning itself is not the mediating process, but the reduction of fear and pain catastrophizing (Mannion et al, 1999; Smeets et al, 2006b). The general lack of exercise treatment specificity therefore suggests that the main effects of therapeutic exercise are produced not through the reversal of physical weaknesses targeted by the corresponding exercise but rather through some 'central' effect perhaps involving an adjustment of perception in relation to pain and disability (Mannion A et al, 1999). However it is now acknowledged that the use of physiotherapy in the multidimensional context has proved the more appropriate model due to the complexity of the development of pain and its presentation in many circumstances (Waddell, 1992).

Fordyce produced a therapeutic approach to the behavioural management of pain (Fordyce, 1976), especially when pain is not viewed as a symptom of tissue damage alone and Turk applied these cognitive principles in 1983 (Turk, Meichenbaum and Genest, 1983). Subsequently cognitive behavioural practice has developed as the main approach in pain management and has been widely used and evaluated since the 1980s. The IASP has emphasized the need for interdisciplinary management of patients with chronic pain and for attention to the physical, psychological, social, vocational, recreational, and other functional aspects of persons with pain-related disability (Loeser JD et al, 1990). Accordingly, physiotherapy with its ability to provide treatment for local spinal problems and their secondary functional changes, reorganize altered physiological patterns and improve the psychosocial state of the patient is acknowledged as part of the multidisciplinary management of pain (Bonica, 1990). This level overlaps and integrates with the field of occupational therapy (training of work related tasks) and psychotherapy.

Clinical guidelines for low back pain published in the New Zealand Journal of Physiotherapy (accrued from library databases at the University of South Australia and various Internet search engines), reviewed nine eligible guidelines differing in their strength of evidence, diagnostic criteria, interventions and measures of outcome providing guideline features: clinical decisionmaking systems, clinical care recommendations, best practice management strategies (patient handouts) and clinical indicators for quality improvement. These guidelines advocated patientcentred outcomes and assumed that practitioners had access to the information and applied the recommendations effectively (Grimmer K et al, 2002).

In both the developing and developed countries, patients may not have access to, or their economic status may exclude them from, the combined efforts of the physiotherapist, occupational therapist and psychotherapist. It is often encumbent upon the physiotherapist in these situations to acquire the relevant knowledge pertaining to pain rehabilitation to guide the patient towards achieving independence and control of the pain.

It is suggested that recommendations for future guidelines would benefit from recent information and studies collated by the IASP on rehabilitation and physical therapy modalities that have been identified as beneficial to patients with chronic pain.

The following suggestions for physiotherapy in the management of chronic low back pain are:

- Recognition of a broad biopsychosocial model of health (and illness) and the positive role of activity in health and healing, emphasis on function, rather than impairment, and reliance upon clinical evidence has transformed phyiotherapists' practice. Therefore the development of a patient-centred rehabilitative approach has emerged that emphasizes the restoration of normal movement and function which incorporates physiotherapy as a vital component of the collaborative approach required for effective pain management (Harding, Simmonds and Watson, 1998).

- Pain rehabilitation is a useful and cost-effective approach to chronic pain management.

- The pain rehabilitation model below makes patient's responsible partners in their own progress, enlists the support and assistance of other providers and places all aspects of treatment into a clear and goal-oriented context (Vasudevan SV, 2004).

\section{Principles of rehabilitation}

Rehabilitation is an important component of chronic pain management and should employ a skilled team to:

- Restore function

- Alleviate pain wherever possible

- Improve pain management skills for the patient with persistent pain

Chronic pain rehabilitation may be considered an active treatment as opposed to maintenance

- Active: the patient and the team work directly to improve function and reduce pain within a set time frame. Treatment is designed to 'cure' or 'alleviate' the underlying condition, while improving function.

- Maintenance focuses on self-management (e.g. exercise, cognitive-behavioural) and ongoing symptomatic medical intervention.

The patient must be motivated to, and capable of, participating.

Conditions requiring urgent surgical or medical interventions (e.g. neurological emergency, infection) must be ruled out.

\section{Treatment programme:}

1. Comprehensive assessment: A thorough history and examination leads to clear diagnosis and a structured treatment plan. Treatment must be aligned to presentation of symptoms and the condition. 
"Pain is a subjective phenomenon: believe the patient - elicit the meaning of pain to the patient.

Assess the pain carefully and reassess regularly: as pain cannot be objectively measured, quantify severity and characterize etiology by the patient's description of the pain; include interference with sleep and daily activities; make a diagnosis as specific pains respond to specific treatments and make pain visible to the patient by the use of the visual analogue scale 0 - 10 scale with $0=$ no pain, $10=$ worst imaginable. (Notes from Guidelines for Assessing and Treating Pain from: Massachusetts General Hospital Cares About Pain Relief Programme Project Director TE Quinn, 2002)".

"Physiotherapy clinical assessment has traditionally relied on clinical tests of impairment but these tests correlate poorly with patients' pain and dysfunction. These tests of muscle strength and range of motion in isolation lack sensitivity, specificity and responsiveness. The best performance testing is quick, simple and meaningful to both the patient and practitioner. Patients with pain tend to move more slowly than pain-free persons, generate less force during muscle testing and may have poor endurance during exercise. The physical performance battery (PPB) measures time taken and distance reached or walked during a set of tasks. The PPB was developed for use with persons with low back pain and it has demonstrated good intra- and inter-rater reliability and stability over time and differentiates patients from pain-free controls. The assessment battery of Harding et al. for use in a diverse chronic pain population detects change following pain management (Notes from Pain Clinical Updates Harding et al,1994)".

2. Treatment: Multiple concurrent interventions designed to address all issues

\section{Physical and occupational therapy}

4. Explanation and education of the patient on chronic back pain

5. Exercise - the most common treatment method and likely the most effective.
Different specific exercise programmes are appropriate for patients with different pain conditions. They include:

1. Postural training and stabilisation

2. Stretching

3. Strengthening

4. Home exercise programme tailored to the individual - this is vital

5. Aerobic conditioning

6. Work conditioning/ work hardening/ activities of daily living (ADL)

7. Ergonomic modifications

8. "Take advantage of the patient's ability to learn and use their own internal resources.

Involve the patient in creating and assessing the plan of care; teach the patient about pain and the many ways it can be treated; teach the patient about self-care strategies such as self-hypnosis, meditation, distraction and bio-behavioural techniques (Quinn TE, 2002)".

9. Modalities used in conjunction with active exercises (thermal, massage, electrical stimulation, traction, transcutaneous electrical nerve stimulation (Tens), myofascial release, dry needling, mobilization (Geisser ME et al, 2005), acupuncture (Thomas et al, 2006) where appropriate). Many patients achieve transient relief with these approaches and therefore should be used sparingly in these particular individuals, however many patients do attain lasting or complete relief.

Despite the long history of the availability and use of physical rehabilitation approaches, traditional medicine in western societies has generally deemphasized physical approaches and has focused on pharmacologic and surgical interventions for pain problems. However many Third World countries, have relied on physical approaches for the management of pain problems because they are easily available, inexpensive, noninvasive, associated with less morbidity and foster independent functioning (Vasudevan SV, 1996). Modern physical approaches that have proved successful through evidence based science can assist and make a valuable contribution to advancing concepts in pain medicine.
Recent advances in neurophysiology and modulation of pain and its perception provide a clearer rationale for the use of physical agents for rehabilitation of patients with pain and related disability (King et al, 1992).

Electrical pain modulation occurs through sensory neuromodulation of peripheral and central nerve impulses. The rationale is based on the concept of a gating mechanism in the dorsal horn of the spinal cord where small diameter, unmyelinated $\mathrm{C}$ and thinly myelinated $\mathrm{A}$ delta fibre activity can be modulated (suppressed) by the larger diameter myleinated A beta fibre activity, thus reducing pain (Woolf and Thompson, 1995). Studies have identified endogenously produced opioid-like substances that are produced by these different frequencies of Tens such as enkephalin and endorphin which have potent opioid agonist activity. High frequency (100 $200 \mathrm{~Hz}$ ), low intensity Tens stimulation involves the spinal segmental inhibitory GABAergic interneuron in the spinal cord and activates delta opioid receptors in the spinal cord and rostroventral medulla. Sluka et al (1999) found that higher frequencies and longer periods of application (at least 40 mins) were more effective in achieving pain relief than previously thought and less likely to produce tolerance. Low frequency (1$4 \mathrm{~Hz}$ ), high intensity Tens affects the opioid pathways through the mu opioid receptors and these affect central mechanisms at both spinal cord and brainstem sites that exert mainly inhibitory effects (Ainsworth L et al, 2006). Other studies have demonstrated that low frequency also activates peripherally located alpha-2A adrenergic receptors which may impact on sympathetically mediated pain.

Other changes in tissue also affect pain relief such as decreasing inflammation, oedema, improving circulation and in mobility and strength. The rationale for these concepts is due to the fact that biological systems are known to be greatly affected by electrical treatment (Cheng et al, 1982). Different types of current have different effects on the body particularly: modulated direct current that reduces inflammation and oedema, improves circulation and affects peripheral temperature changes, inter- 
rupted direct or surged currents that produce functional (motor nerve) electrical stimulation that impacts upon strength and mobility, microcurrents that are mostly subliminal that produce endorphins and affect wound healing, hyperaesthesia, inflammation and aberrant nerve conditioning and cranial microcurrent that increases endorphins, improves aberrant nerve conditioning and induces relaxation.

"Use of non-pharmacologic approaches should be used to complement, not replace, appropriate analgesic therapy (Quinn TE, 2002)".

An ALGORITHM has been developed below that may assist in deciding best treatment practice when using electrical modulation for pain relief and healing. The principle of the algorithm assumes that Tens, when used for three days continuously for eight hours per day at home may in at least $10 \%$ of patients provide complete relief of pain and restore full mobility and others may improve pain by at least $60 \%$ while $20 \%$ may have no response (Berger P 1999). If the desired response is achieved then the patient may move towards complete rehabilitation but if this is not achievable other modalities are applied that may bring the patient into better alignment with pain relief. Patients who are treated with a combination of physical treatment in the clinic should experience TENS for at least 40 mins to achieve optimal results.

Patients who experience hyperaesthesia and or allodynia may best be suited with subliminal microcurrent therapy, acupuncture and cranial electrotherapy (CES) to activate central mechanisms to increase endorphins and induce relaxation. Other techniques such as breathing exercises, visualization and self-hypnosis also activate the descending mechanisms to increase endorphins. Explanation, information, advice on pain and its treatment and reducing fear are also important factors in supporting these descending mechanisms.

Functional electrical stimulation (FES) is an important part of re-establishing a connection from the periphery to the brain. The motor cortex often receives misinformation from the periphery due to injury and disuse in chronic pain

Diagram: Algorithm for the use of electrical and physical modalities in chronic back pain.

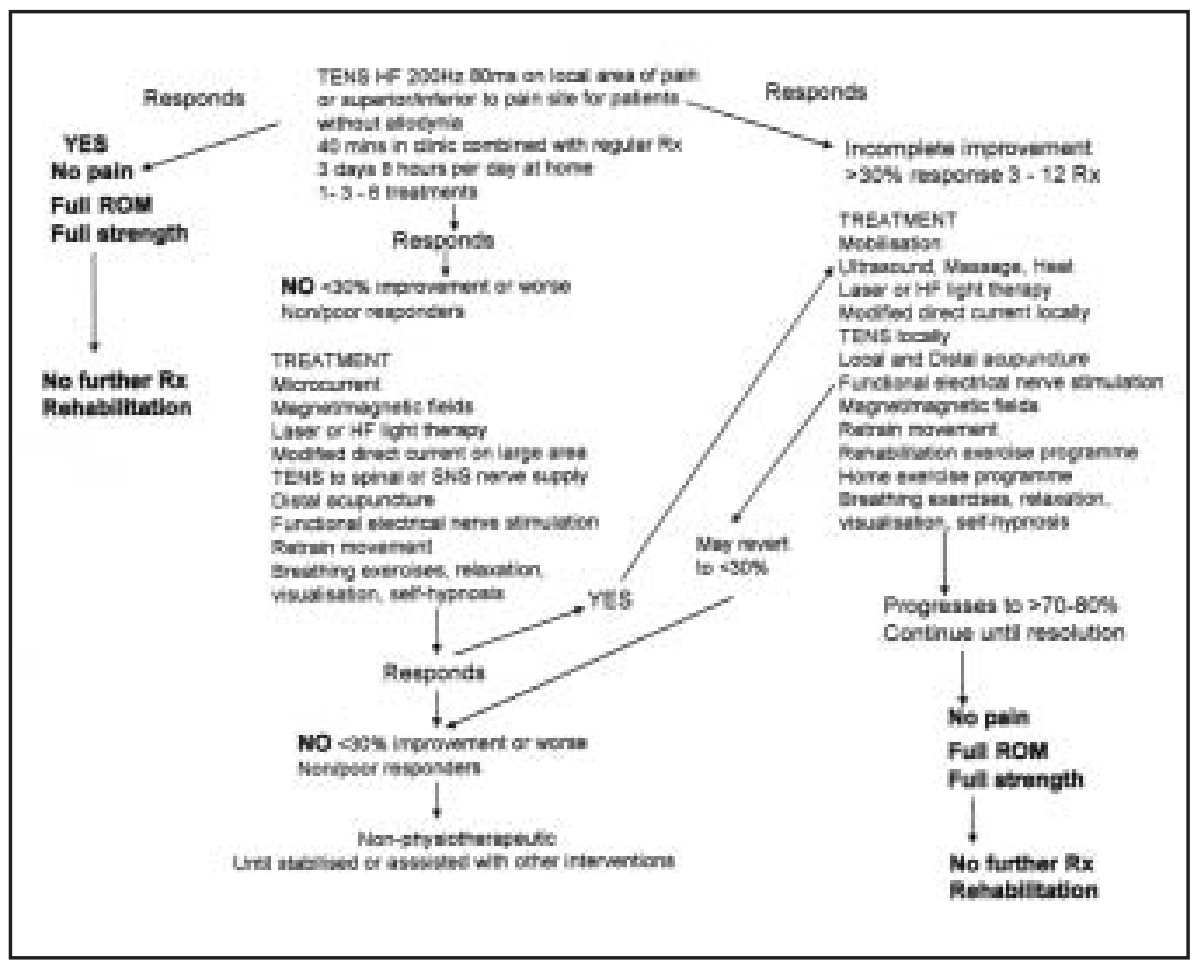

situations and FES strengthens weakened muscle fibres, assists with improved function, mobilizes joints and improves co-ordination. Using mirrors according to Moseley (2005), to improve mobility helps with discordance between motor intent and movement. It is discovered that when the disused limb is hidden from view behind a mirror, the patient is then asked to move the unaffected limb and to observe this movement in the mirror. The patient now sees the mirror image of the unaffected leg as it now appears to be the affected leg and this provides a fake/unreal visual of information that provides a new connection to the motor cortex from the disused limb. There is often improvement in the affected limb after persevering with this activity.

\section{A model of advancement toward reha- bilitation supported by the IASP in Clinical Updates on Physical Therapy for Chronic Pain provides the follow- ing input (Harding VR et al 1998): \\ Planning and pacing assists the patient with a balance between exercise and support. It encourages rest for the injured area and prevention of re-injury through use of orthotic devices (braces, corsets, splints).}

Activity, activity related goal setting, and pacing play key roles in the rehabilitation of patients with chronic pain. Pacing and goal setting even out the activity peaks and troughs controlled by pain so as to achieve a moderate activity-rest cycle. Gradual controlled increases in general activity level will avert triggering sudden increases of pain that lead to reduction of activity. Activities are paced by timing and/or the introduction of exercise quotas interspersed with periods of rest or a different activity. Establishing specific, challenging but attainable goals can actually facilitate task performance and results from meeting expectations of efficacy and outcome. Belief that a specific outcome can be achieved by a specific behaviour may be the most potent determinants of change during rehabilitation. Increased self-efficacy is closely linked to successful rehabilitation as a positive outcome that is defined as increased activity, improved coping and reduced pain behaviour. Confidence is often low when tackling new goals or returning to previously abandoned activities. To increase confidence, patients need to attempt something previously feared, achieve it, and recognize it as their own achievement. Persistent 
goal attainment will re-enforce selfefficacy and lead to the perception of mastery over the problem or task. Goal setting should be a matter of negotiation between the patient and the therapist and should always be personally relevant, interesting, measurable and achievable to the patient, both functionally and socially.

Exercise regimens should be regular and gradually increase in duration and intensity. Adherence is greatest with exercises that are easily incorporated into a patient's routine and the patient is more likely to participate in exercises/ activities that are interesting and if others are involved. Good information about exercise/classes to assist patients in making choices, overcoming unhelpful beliefs and modifying behaviour (increasing activity and exercise) is advocated.

Inevitably, patients may experience exacerbation of the pain problem at some time which should never be seen as a failure or of the patients' inability to manage the condition. Identification of a physical event and or cumulative psychological stresses that caused the relapse can be helped by the physiotherapist who will suggest strategies to cope with the situation such as visiting health professionals, use of pain medication, physical modalities that ease pain, brief rest or relaxation and then a rapid plan for resumption of activities. Plans to resume activities are critical as it provides an action plan in readiness for exacerbations that can help the patient retain a sense of control.

\section{CONCLUSION}

Rehabilitation for chronic pain sufferers is a life less dominated by pain and can be long and complex and involves overcoming physical and psychological obstacles. The physiotherapist helps patients: address obstacles to rehabilitation, use information accurately, provide helpful feedback and reinforcement to guide efforts towards a return to activities and achievement of valued personal goals.

\section{REFERENCES}

Ainsworth L, Budelier K, Clinesmith M. et al 2006. TENS reduces chronic hyperalgesia induced by muscle inflammation. Pain: 120: 182-187.

Airaksinen O, Brox JI, Cedraschi C, Hildebrandt J, Klaber-Moffett J, Kovacs F, et al 2006. European guidelines for the management of chronic non-specific low back pain. European Spine Journal: 15 (4): S192-300.

Berger P. 1999. The role of the physiotherapist in the treatment of complex regional pain syndromes. Pain Reviews: 6: 211-232.

Berger P, Matzner L. 1999. Study on osteoarthritis of the knee comparing the effects of Action Potential Simulation Therapy with Tens and Placebo. South African Journal of Anaesthesiology and Analgesia: 5: 26-39.

Bonica JJ. 1990. (Ed) The Management of Pain, 2nd ed. Lea and Febiger, Philadelphia.

Bousema EJ, Verbunt JA, Seeden HAM, Vlaeyen JWS, Knottnerus JA. 2007. Disuse and physical deconditioning in the first year after the onset of back pain. Pain: 130: 279-86.

Cheng N, Van hoof H, Bockx E et al. 1982. The effects of electric currents on ATP generation, protein synthesis and membrane transport in rat skin. Belgian National Foundation of Medical Research.

Croft PR, Dunn KM. 2007. Course and prognosis of back pain in primary care: The epidemiological persective. Editorial. Pain: 122: 1-3.

Dionne CE. 1999. Low back pain. In: Crombie IK, Croft PR, Linton SJ, Leresche L, Von Korff M, editors. Epidemiology of Pain. International association for the Study of Pain (IASP) Press.

Enthoven P, Skargren E, Carstensen J, Oberg B. 2006. Predictive factors for 1 -year and 5-year outcome for disability in a working population of patients with low back pain treated in primary care. Pain: 122 : 137-44.

Ferreira ML, Ferreira PH, Latimer J, Herbert R, Maher CG. 2002. Does spinal manipulative therapy help people with chronic low back pain? Australian Journal of Physiotherapy: 48: 277-84.

Ferreira PH, Ferreira ML, Maher CG, Herbert RD, Refshauge K. 2006. Specific stabilization exercise for spinal and pelvic pain: a systematic review. Australian Journal of Physiotherapy: $52: 79-88$.
Ferreira ML, Ferreira PH, Latimer J, Herbert RD, Hodges PW, Jennings MD, Maher G, Refshauge KM. 2007. Pain: 131: 31-37.

Fordyce WE. 2004. Behavioural Methods for Chronic Pain and Illness, In: 1976 Mosby CV, St Louis, MO. Frost H, Lamb SE, Doll HA, Taffe Carver P, Stewartson Brown. Randomised controlled trial of physiotherapy compared with advice for low back pain. British Medical Journal: 329: 708.

Geisser ME, Wiggert EA, Haig AJ, Colwell MO. 2005. A randomised controlled trial of manual therapy and specific adjuvant exercise for chronic low back pain. Clinical Journal of Pain: Vol 21, No 6: 463-470.

Grimmer K, Milanese S, Bialocerkowski A. 2002. Clinical Guidelines for Low Back Pain: Physiotherapy Perspective Physiotherapy Canada: 55: 185-193.

Grotle M, Brox JI, Veierod MB, Vollestad NK. 2005: Clinical course and prognostic factors in acute low back pain: patients seeking help for their first time. Spine: 30(8): 976-82.

Harding VR, Simmonds MJ and Watson PJ. 1998. Physical therapy for chronic pain IASP Pain Clinical Updates: Vol VI, Issue 3.

Harding VR, Williams AcdeC et al. 1998. Pain 1994; 58:367-375 In: Pain Clinical Updates Physical Therapy for Chronic Pain : Vol VI, Issue 3.

Hay EM, Mullis R, Lewis M, Vohora K, Main CJ, Watson P, et al. 2005. Comparison of physical treatments versus a brief pain management programme for back pain in primary care: a randomized clinical trial in physiotherapy practice. Lancet: 365 (9476): 2024-30.

Hayden JA, van Tulder MW, Malmviaara A, Koes BW. 2005. Exercise therapy for treatment of non-specific low back pain. Cochrane Database Systematic Review: CD000335

Hides JA, Richardson CA, Jull GA, Davies SE. 1995. Ultrasound imaging in rehabilitation. Australian Journal of Physiotherapy: 41:187-93.

Jellema P, van der Windt DA, van der Horst HE, Twisk JW, Stalman WA, Bouter LM. 2005. Should treatment of (sub) acute low back pain be aimed at psychological prognostic factors? Cluster randomized clinical trial in general practice. British Medical Journal: 331(7508): 84.

Kalauokalani D, Cherkin DC, Sherman, Koepsell TD, Deyo RA. 2001. Lessons from a trial of acupuncture and massage for low back pain: patient expectations and treatment effects. Spine: (13): 1418-24. 
King JC. et al. 1992. Pain Digest: 2:106-126 In: Physical Rehabilitation in Managing Pain

Lahad A, Malter AD, Berg AO. Deyo RA. 1994. The effectiveness of four interventions for the prevention of low back pain. Journal of the American Medical Association: 272 (16): 1286-91.

Linton SJ. 2000. A review of psychological risk factors in back and neck pain. Spine: 25 (9): 1148-56.

Linton SJ. 2001. Occupational psychological factors in crease the risk for back pain: a systematic review. Journal of Occupational Rehabilitation: 11(1): 53-66.

Loeser JD, et al. 1990. Desirable characteristics for pain treatment facilities (guidelines) Seattle IASP.

Mannion A, Muntener M, Taimela S, Dvorak J. 1999. Volvo Award Winner in Clinical Studies: Randomised controlled clinical trial of three active therapies for chronic low back pain. Spine: 24 (23): 2435.

Moseley GL, Gandevia SC. 2005. Sensorymotor incongruence and reports of pain. Rheumatology: 44: 1083-1085.

Nielson WR, Weir R. 2001. Biosychosocial approaches to the treatment of chronic pain. The Clinical Journal of Pain: Vol 17, No 4; S114-S127.

Quinn TE. 2002. Project director Ten Guidelines for Assessing and Treating Pain from: Massachusetts General Hospital Cares About Pain Relief Programme Published in Pain Relief Connection: Vol 1: 2-9.

Richardson CA, Jull GA, Hides JA, Hodges P. 1999. Therapeutic exercise for spinal stabilization in low back pain. New York: Churchill Livingston.

Sluka KA, Deacon M, Stibal A, Strissel S, Tempstra A. 1999. Spinal blockade of opioid receptors prevents the analgesia produced by TENS in arthritic rats. Journal of Pharmacology and Experimental Therapeutics: 289: 840-846.

Sluka KA, Wu G-C, Chung JM. 2006. Recent Insights into Analgesic Mechanisms of Acupuncture and TENS In: Proceedings of the 11th World Congress on Pain, (eds) Flor H, Kahn E, Dostrowsky JO, IASP Press, Seattle: 75: 862.

Smeets RJEM, Vlaeyen JWS, Kester ADM, Knottnerus JA. 2006b. Reduction of pain catastrophizing mediates the outcome of both physical and cognitive-behavioural treatment in chronic low back pain. Pain: 7: 261-71.
Teyhen DS, Miltenberger CE, Deiters HM, Del Toro YM, Pulliam JN, Childs JD, et al. 2005.The use of ultrasound imaging of the abdominal drawing in maneuver in subjects with low back pain. Journal of Orthopaedics Sports physical Therapy: 35: 346-55.

Thomas KJ, MacPherson H, Thorpe L, Brazier J, Fitter M, Campbell MJ, Roman M, Walters SJ, Nicholl J. 2006. Randomised controlled trial of a short course of traditional acupuncture compared with usual care for persistent nonspecific low back pain. British Medical Journal: 333: 623.

Turk DC, Meichenbaum D and Genest M. 1983. Pain and Behavioural Medicine: the Cognitive-Behavioural Approach. Guildford Press, New York.

Vasudevan SV. 1996. Physical Therapy Modalities Faculty lectures from 7 th International Symposium: The Pain Clinic VII: $6: 477-502$.

Vasudevan SV. 1997. Pain: Clinical Updates Raj et al. (Eds) Monduzzi: Vol V, Issue 3.
Vasudevan SV. 2004. Guidelines for the assessment and management of chronic pain Wisconsin Medical Society Task Force on Pain Management Wisconsin Medical Journal: Vol 103, No 3:14-27.

Van Tulder M, Malmivaara A, Esmail R, Koes B. 2000. Exercise Therapy for Low Back Pain: A systemic review within the framework of the Cochrane Collaboration Back Review Group. Spine: 25 (21): 2784-2796.

Von Korff M, Miglioretti DL. 2005. A prognostic approach to defining chronic pain. Pain: 117 (3): 304-13.

Waddell G. 1998. The back pain revolution. London: Churchill Livingston.

Waddell G. 1992. Biopsychosocial Analysis of Low Back Pain Clinical Rheumatology: Vol 6 (3) 5523-57.

Woolf CJ, Thompson. 1995. Stimulationinduced analgesia: Transcutaneous electrical nerve stimulation (TENS) and Vibration. In: Textbook of Pain, 3rd ed., eds Wall PD, Melzack R. Edinburgh, UK: Churchill Livingstone: 1206. 